\title{
Development of a SGJ-1 of Water-Based Anti-Wax Agent
}

\author{
Lejun Liao', Wenzhe Han', Qichao $\mathrm{Cao}^{2}$, Xintong $\mathrm{Li}^{2}$, Li He${ }^{2}$, Song Wang² \\ ${ }^{1}$ Xianyang Chuanqing Xinyuan Engineering Technology Co., Ltd., Xianyang, China \\ ${ }^{2}$ Changjiang University, Jingzhou, China \\ Email: 1096448904@qq.com
}

How to cite this paper: Liao, L.J., Han, W.Z., Cao, Q.C., Li, X.T., He, L. and Wang, S. (2021) Development of a SGJ-1 of Water-Based Anti-Wax Agent. Open Journal of Yangtze Gas and Oil, 6, 72-82.

https://doi.org/10.4236/ojogas.2021.62007

Received: March 12, 2021

Accepted: April 27, 2021

Published: April 30, 2021

Copyright $\odot 2021$ by author(s) and Scientific Research Publishing Inc. This work is licensed under the Creative Commons Attribution International License (CC BY 4.0).

http://creativecommons.org/licenses/by/4.0/ (c) (i) Open Access

\begin{abstract}
The phenomenon of petroleum wax deposition is very common during oil well production. When the wax molecule condenses on the surface of the pipeline, it will hinder the exploitation of crude oil, reduce the recovery rate of crude oil, and may lead to the blockage of the pipeline when it is serious, so that the oil recovery work will stop. This phenomenon can be obviously changed by using wax cleaning agent. However, the low ignition point and toxicity of oil-based wax remover are not conducive to oil recovery. Therefore, a new water-based paraffin remover SGJ-1 was developed in this paper. The best formula is: wax dispersant $15 \%$, wetting reversion agent $1 \%$, sodium silicate $1 \%$, alcohol cosolvent $8 \%$ and $75 \%$ water. Condensation point, wax dissolution rate and anti-wax performance of SGJ-1 water-based dewaxing and anti-waxing agent were tested by self-assembly testing device. The experimental results show that the condensation point of SGJ-1 is $-34^{\circ} \mathrm{C}$, the viscosity reduction effect is good under $35^{\circ} \mathrm{C}$, and the wax dissolution rate is $0.0512 \mathrm{~g} / \mathrm{min}$, The highest wax prevention rate can reach $89.58 \%$ and the wax removal and wax prevention ability is excellent. Compared with other paraffin removers, SGJ-1 can also reduce the viscosity of crude oil, so it has a good development prospect.
\end{abstract}

\section{Keywords}

Water-Based Anti-Wax Agent, Oil Well Waxing, Wax Dissolution Rate, Anti-Wax Rate, Performance Evaluation

Wax cleaning agent has become one of the most important links in oil mining industry. A good wax cleaning agent may determine the smooth production of oil. However, with the development of science and technology and the strengthening of people's awareness of environmental protection and safety in production, the ordinary wax cleaning agent has not met the needs of the current mining operations, nor does it meet the [1] [2] of complex stratigraphic conditions. 
At present, the main wax cleaning agents are oil based wax cleaning agent, water based wax cleaning agent and emulsion wax cleaning agent [3] [4] [5]. Oil based wax remover does not belong to environmental friendly products, most of the components in the compound organic solvent added are low ignition point, and the toxicity is very large, the use process is very unsafe, easy to fire, and underground accidents occur. Water based wax remover is a kind of water as dispersing medium, which has surfactant, sometimes intersolvent or alkaline substance [6] [7] [8]. The function of the active agent is wetting inversion, making the waxy surface turn into a hydrophilic surface, which is conducive to the wax falling off the surface, but not conducive to the deposition of wax [9] [10]. In the research of paraffin removal technology, Chinese scholars have found that a good and environmentally friendly water-based paraffin removal agent can be obtained by mixing with surfactants. In this paper, on the basis of drawing lessons from previous studies, through screening different surfactants, is committed to the research of a new water-based paraffin remover with good paraffin removal effect and can reduce the viscosity of crude oil. Compared with oil-based wax remover is more safe and efficient, no odor, no pollution. Can bring better economic benefits for enterprises, application prospects are very broad.

\section{Experimental Part}

\subsection{Experimental Materials}

Main experimental drugs: 60\# paraffin, methyl stearate polyoxyethylene ether, fatty acid methyl ester ethoxy sulfonate, surfactant, methanol, ethanol, n-butanol, sodium silicate.

Main experimental instruments: digital display constant temperature water bath pot, timing electric agitator, petroleum product freezing point tester, rotary viscometer self-assembly wax rate measuring device, wax prevention rate measuring device.

\subsection{Wax Dissolution Rate Measuring Device, Formula and Measuring Steps}

The schematic diagram of the measuring device is shown in Figure 1.

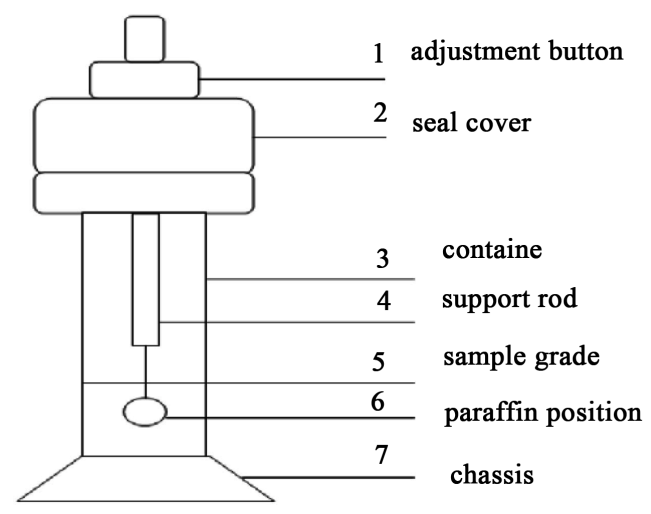

Figure 1. Schematic diagram of wax dissolving device. 
The formula for the rate of wax dissolution:

$$
v=m / t
$$

$v$ (g/min): Wax dissolution rate; $m(\mathrm{~g})$ : Paraffin quality; $t$ (min): Time required to dissolve paraffin.

First, the paraffin wax needed to be tested was dissolved and placed in the paraffin mold of device 6 to make it fully compatible with the mold. After cooling, the paraffin wax was taken out and weighed with electronic balance, and the paraffin quality was recorded accurately to $0.01 \mathrm{~g}$. Then, the wax removal samples to be tested were added to the water temperature control in $50^{\circ} \mathrm{C} \pm 1{ }^{\circ} \mathrm{C}$ digital constant temperature water bath pot. After the wax removal samples were kept constant temperature, the paraffin wax was invaded into the wax removal samples and the time of complete dissolution of paraffin was recorded. Finally, the wax dissolution rate is calculated by the formula.

\subsection{Determination of Wax-Proof Rate, Formula and Procedure}

The schematic diagram of the measuring device is shown in Figure 2.

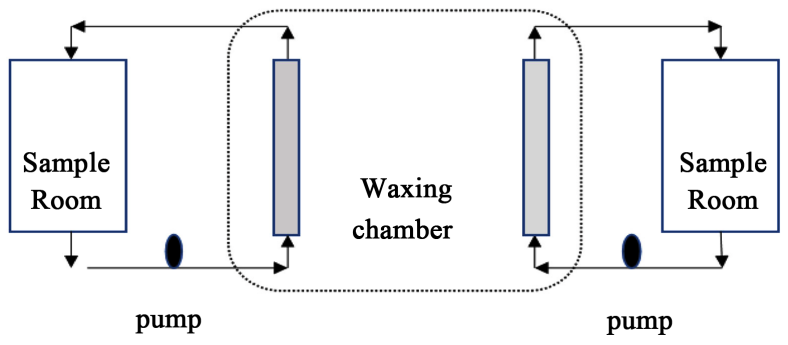

Figure 2. Schematic diagram of anti-wax measuring device.

Wax proof formula:

$$
n=\left[\left(m_{1}-m_{2}\right) \div m_{1}\right] \times 100 \%
$$

$n$ : Wax proof; $m_{1}$ : Wax deposition without wax remover; $m_{2}$ : Deposition with wax remover. The pump in the device is a magnetic pump, and two waxing tubes are placed in the waxing chamber as the test tube and reference tube of paraffin wax.

The test steps are as follows: first, two $500 \mathrm{ml}$ beakers are added, $200 \mathrm{~g}$ of diesel oil and $50 \mathrm{~g}$, of paraffin wax are added to dissolve , $50 \mathrm{~g}$ of ethanol and 50 minutes of distilled water are added, and the agitator is used to stir evenly for 15 minutes. Clean up the wax pipe and install it in the wax chamber. After that, two samples were added to the sample room, one of which was added to the SGJ-1 wax remover. The temperature of the sample chamber is stable at $45^{\circ} \mathrm{C} \pm 1^{\circ} \mathrm{C}$ and the temperature of the waxing chamber is between $35^{\circ} \mathrm{C} \pm 1^{\circ} \mathrm{C}$. At the same time, the magnetic pump is opened and the sample is stirred evenly with agitator for 40 minutes. When the equipment is cooled to room temperature, the wax tube is removed and weighed. The accurate value is $0.01 \mathrm{~g}$. The Record wax deposition without wax remover and SGJ-1 wax remover. Finally, the formula is brought into the calculation. 


\section{Experimental Process}

Water-based anti-wax agent is composed of water, wax-soluble dispersant, alcohol cosolvent, solubilizing dispersant, wetting reversal agent and alkali. Among them, the components can be mixed with water in any proportion to form water-based cleaning wax inhibitor [11] [12]. How to configure an efficient water-based cleaning wax inhibitor needs to optimize the selection of each component. The optimal solution was $10 \%-15 \%$ wax dissolving dispersant, $1 \%$ - 5\% wetting reversal agent , $3 \%-8 \%$ alcohol cosolvent and $0.5 \%-2.0 \%$ sodium silicate. Determine the optimal formula of water-based cleaning wax inhibitor.

\subsection{Selection of Wax Dissolving Dispersant}

When the molar ratio of methyl stearate polyoxyethylene ether to fatty acid methyl ester ethoxylated sulfonate was 3:1, the wax dissolving dispersant was obtained. The wax dissolving rate of different doses of wax dissolving dispersant was measured in Table 1.

Table 1. Wax-dissolving rate added by dispersant.

\begin{tabular}{cc}
\hline Add wax dissolving dispersant $/ \%$ & Wax dissolution rate $/(\mathrm{g} / \mathrm{min})$ \\
\hline 10 & 0.0236 \\
11 & 0.0254 \\
13 & 0.0271 \\
14 & 0.0292 \\
15 & 0.0309 \\
\hline
\end{tabular}

\subsection{Selection of Wetting Reversal Agents}

Surfactant can play a good wetting and inversion effect on paraffin wax, and can transform the waxing surface of oil well species into hydrophilic surface, which can not only remove wax, but also play the role of wax prevention. It is an indispensable part of water based wax cleaning and wax prevention agent [13] [14] [15]. Seven kinds of surfactants, such as Tween20, Tween80, JFC-2, CLD510, CLD-3P, OP-10, MOA-3B, were used to determine the wetting reversal agent. At the same time, according to the HLB value of the surfactant, the wetting reversal agent was obtained by compounding the JFC-2 and OP-10 molar ratio of 1:3. Determination the wax dissolution rate after adding different doses of wetting reversal agent is shown in Table 2.

Table 2. Wax dissolution rate added by wetting reversal agent.

\begin{tabular}{cc}
\hline Wetting reversal agent plus/\% & Wax dissolution rate $/(\mathrm{g} / \mathrm{min})$ \\
\hline 1 & 0.0241 \\
2 & 0.0263 \\
4 & 0.0279 \\
5 & 0.0316 \\
\hline
\end{tabular}


As can be seen from this table, after the addition of wetting reversal agent containing wax dissolving dispersant, the rate of wax dissolving has not been obviously improved, which is because the HLB value of the selected surfactant is the main determinant of the surfactant ability or not.

\subsection{Selection of Alcohol Cosolvent}

When the molar ratio of methanol, ethanol and n-butanol was 3:2:1, the alcohol cosolvent was obtained. The wax dissolution rate of alcohol cosolvent with different doses was determined as shown in Table 3.

Table 3. Effect of solvent addition on wax dissolution rate.

\begin{tabular}{cc}
\hline Alcohol cosolvent addition/\% & Wax dissolution rate $/(\mathrm{g} / \mathrm{min})$ \\
\hline 3 & 0.0275 \\
4 & 0.0293 \\
5 & 0.0311 \\
7 & 0.0326 \\
8 & 0.0348 \\
\hline
\end{tabular}

\subsection{Alkali Addition Selection}

Sodium silicate, also known as vesic flower alkali, can not only adjust its acid and base, but also make the asphaltene of oil field wax more easily dispersed in water. Because some groups in asphaltene can change with alkali, many nuclei can be formed by wax, and these suspended nuclei can be taken away by the flow of crude oil, so as to achieve the purpose of dewaxing. When sodium silicate was added $0.5 \%-2.0 \%$, the water-based anti-wax agent was alkaline. The wax dissolution rate and $\mathrm{PH}$ value after adding different doses of sodium silicate were measured as shown in Table 4.

Table 4. Wax dissolution rate and $\mathrm{PH}$ value after adding sodium silicate.

\begin{tabular}{ccc}
\hline Sodium silicate/\% & Wax dissolution rate/(g/min) \\
\hline 0.5 & 0.0301 & 7.2 \\
1.0 & 0.0314 & 7.6 \\
1.5 & 0.0325 & 8.0 \\
2.0 & 0.0348 & 8.2 \\
\hline
\end{tabular}

Through the data in Tables $1-4$, we find that when the wax dissolution rate is determined after adding the components of water-based wax cleaning agent in turn, although with the addition of these four components, the wax dissolution rate has been slowly increased. But the effect is not particularly obvious. Finally, after adding sodium silicate, the water-based wax-cleaning agent has been weakly alkaline. Compared with the expensive material cost, it is not feasible to simply pursue the addition of four components to make the water-based wax-cleaning agent. Therefore, the following formula optimization experiments are carried out. 


\subsection{Formula Selection of Water-Based Anti-Waxants}

Orthogonal experiment was conducted with different dosage of dispersant, wetting reversion agent, alcohol cosolvent and sodium silicate as the factors, and the dispersant rate of wax as the index. Factor levels are shown in Table 5.

Table 5. Level of factors.

\begin{tabular}{ccccc}
\hline & A & B & C & D \\
\cline { 2 - 5 } Level & $\begin{array}{c}\text { Solving wax } \\
\text { dispersants Content/\% }\end{array}$ & $\begin{array}{c}\text { Wetting reversal } \\
\text { agent Content/\% }\end{array}$ & $\begin{array}{c}\text { Sodium silicate } \\
\text { Content/\% }\end{array}$ & $\begin{array}{c}\text { Alcohol cosolvent } \\
\text { Content/\% }\end{array}$ \\
\hline 1 & 11 & 1 & 1.0 & 3 \\
2 & 13 & 3 & 1.5 & 5 \\
3 & 15 & 5 & 2.0 & 8 \\
\hline
\end{tabular}

According to the orthogonal experiment in Table 6 and the data in Table 7, it can be seen that the factors affecting the wax dissolution rate of water-based paraffin repellent agent are $\mathrm{A}>\mathrm{D}>\mathrm{B}>\mathrm{C}$, from large to small.

Table 6. Orthogonal experimental tables.

\begin{tabular}{cccccc}
\hline Serial number & A & B & C & D & Wax dissolution rate/(g/min) \\
\hline 1 & 1 & 1 & 1 & 1 & 0.0326 \\
2 & 1 & 1 & 1 & 2 & 0.0314 \\
3 & 1 & 2 & 2 & 1 & 0.0327 \\
4 & 1 & 2 & 2 & 2 & 0.0319 \\
5 & 2 & 1 & 2 & 1 & 0.0304 \\
6 & 2 & 1 & 2 & 2 & 0.0309 \\
7 & 2 & 2 & 1 & 2 & 0.0346 \\
8 & 2 & 2 & 1 & 2 & 0.0349 \\
9 & 3 & 1 & 2 & 1 & 0.0334 \\
\hline
\end{tabular}

Table 7. Orthogonal results table.

\begin{tabular}{ccccc}
\hline Level & $\mathrm{A}$ & $\mathrm{B}$ & $\mathrm{C}$ & $\mathrm{D}$ \\
\hline $\mathrm{K} 1$ & 0.0322 & 0.0330 & 0.0328 & 0.0321 \\
$\mathrm{~K} 2$ & 0.0311 & 0.0322 & 0.0322 & 0.0323 \\
$\mathrm{~K} 3$ & 0.0343 & 0.0323 & 0.0327 & 0.0332 \\
$\mathrm{R}$ & 0.0032 & 0.0008 & 0.0006 & 0.0011 \\
\hline
\end{tabular}

The optimum formula for water-based anti-wax agent is $A_{3} B_{1} C_{1} D_{3}$, That is Solving wax dispersants: $15 \%$; Wetting reversal agent: $1 \%$; Sodium silicate: $1 \%$; Alcohol cosolvent: 8\%.

\section{Evaluation of Experimental Results}

The performance of water-based wax-cleaning agent is mainly reflected in the setting point, as well as the effect of using wax-cleaning and wax-proof. To better understand the performance and effect of the developed water-based wax-cleaning 
SGJ-1 in the same field, this paper selects the WPR-I water-based wax-cleaning agent [16] [17], DW8012 water-based wax-cleaning agent and PW8105 wax-proof agent [18]. The YE-60 water-based wax-cleaning agent [19] is used to compare the setting point, wax dissolution rate and wax-proof performance, and the effect of SGJ-1 on the viscosity of crude oil is also measured.

\subsection{Determination of Condensation Point}

Coagulation point refers to the maximum temperature required when the liquid of water-based wax remover changes to the liquid level and does not move the solid. Generally speaking, in the field use process, the setting point of water-based wax remover should be lower than the minimum temperature in local winter. Therefore, the setting point of water-based wax remover is an important index to measure its quality. The results of the determination of condensation points of several water-based dewaxing agents using a petroleum product condensation point tester are shown in Figure 3.

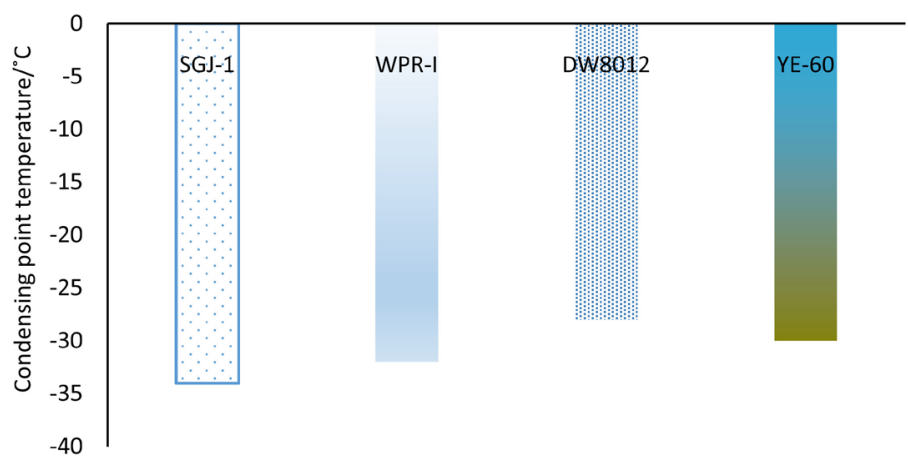

Figure 3. Condensate test results for each product.

Figure 3 shows that the setting temperature of each product of water-based wax remover meets the requirements of use, and the maximum temperature is minus $28^{\circ} \mathrm{C}$. The freezing point temperature of SGJ-1 products is up to minus $34^{\circ} \mathrm{C}$, which can meet the colder winter operations and cope with different climate changes in various places. The scope of application is wider.

\subsection{Study on the Effect of Reducing Viscosity}

Different viscosity of crude oil will make the velocity of crude oil different, and faster velocity of crude oil will lead to lighter waxing degree of crude oil, because faster velocity can reduce the time of crude oil in wellbore and slow down the oil temperature. Wax particles are taken away without more time to deposit in the cylinder wall. The permeability and dispersion of surfactants in water-based wax remover can penetrate into the wax crystal gap, weaken the binding ability of wax molecules, prevent the formation of wax blocks, the viscosity of crude oil is reduced and the fluidity of crude oil becomes stronger. In order to test the viscosity-reducing effect of water-based wax remover, the crude oil in Changqing Oilfield is taken as Sample, crude oil physical properties as shown in Table 8. 
Table 8. Primary oil properties.

\begin{tabular}{ccccc}
\hline $\begin{array}{c}\text { Density g/cm } \\
\left.\text { (in } 20^{\circ} \mathrm{C}\right)\end{array}$ & $\begin{array}{c}\text { Viscosity } / \mathrm{mPa} \cdot \mathrm{s} \\
\left.\text { (in } 50^{\circ} \mathrm{C}\right)\end{array}$ & $\begin{array}{c}\text { Condensation } \\
\text { point } /{ }^{\circ} \mathrm{C}\end{array}$ & $\begin{array}{c}\text { Wax } \\
\text { content } / \%\end{array}$ & $\begin{array}{c}\text { Wax } \\
\text { analysis } /{ }^{\circ} \mathrm{C}\end{array}$ \\
\hline 0.894 & 15.3 & 27 & $14.5-21.5$ & 49 \\
\hline
\end{tabular}

The curves of crude oil viscosity and crude oil viscosity measured at ${ }^{\circ} \mathrm{C}$ temperature of 20 to 50 are shown in Figure 4.

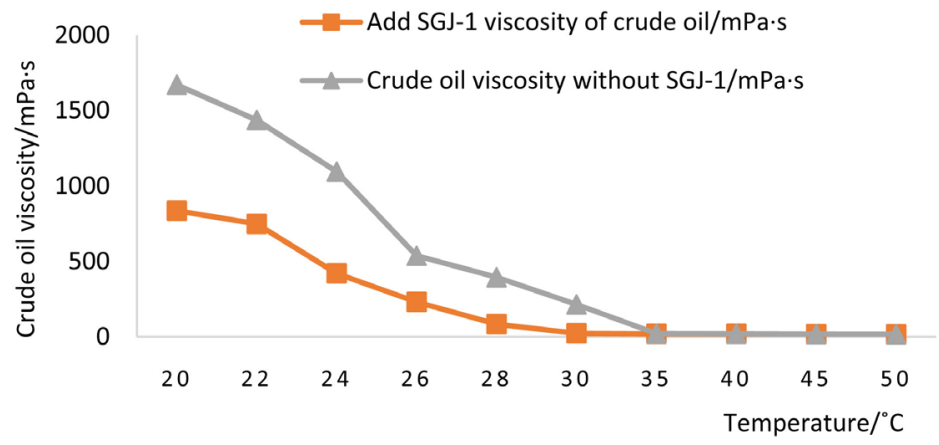

Figure 4. Viscosity change curve.

We can intuitively see from Figure 4 that the viscosity of crude oil after adding SGJ-1 is much lower than that of non-added crude oil. The difference between the two decreases from nearly $800 \mathrm{mPa} \cdot \mathrm{s}$ to almost $0 \mathrm{mPa} \cdot \mathrm{s}$ with the increase of temperature. Before the temperature is $35^{\circ} \mathrm{C}$, the water-based dewaxing agent can reduce the viscosity of crude oil, increase the ability of crude oil to carry wax molecules, and make the waxing ability of crude oil smaller.

\subsection{Evaluation of Wax Dissolution Rate}

The ability of wax dissolving is an important embodiment of the performance of water-based wax cleaning preservatives. We use the self-assembled wax dissolving device and formula to determine the wax dissolution rate of water-based wax cleaning preservatives. The data compared with other products in the same field are shown in Table 9.

Through Table 9, we found that in terms of wax dissolution rate, the wax dissolution rate SGJ-1, water-based wax cleaning agent developed by us reached $0.0512 \mathrm{~g} / \mathrm{min}$, and the wax dissolution ability was higher than that of other water-based wax removal agents in the same field. At the same time, the industry reference standard [20] $0.016 \mathrm{~g} / \mathrm{min}$, wax dissolution effect is very good.

Table 9. Wax dissolution rates for different products.

\begin{tabular}{cc}
\hline Code & Wax dissolution rate $/(\mathrm{g} / \mathrm{min})$ \\
\hline SGJ-1 & 0.0512 \\
WPR-I & 0.0428 \\
DW8012 & 0.0407 \\
YE-60 & 0.0386 \\
\hline
\end{tabular}




\subsection{Evaluation of Dewaxing Rate}

Because crude oil contains a large number of paraffin components, when the oil temperature decreases below the wax analysis point in the production process, the paraffin will precipitate, resulting in wax formation. Water-based anti-waxing agent can effectively reduce paraffin precipitation in crude oil and achieve anti-wax effect. The anti-wax rate is also an efficiency to reduce the precipitation of crude oil paraffin after adding reagent. The higher the anti-wax rate, the better the effect. Test Formula for Wax Resistance in Formula (2).

\subsubsection{Effect of Temperature on Anti-Wax Rate}

Temperature is the main factor affecting the effect of paraffin deposition [21], The anti-wax effect of water-based anti-waxing agent will also be affected by different temperature of formation. The data of anti-wax rate at different temperature of four products measured by experiment in Figure 5 .

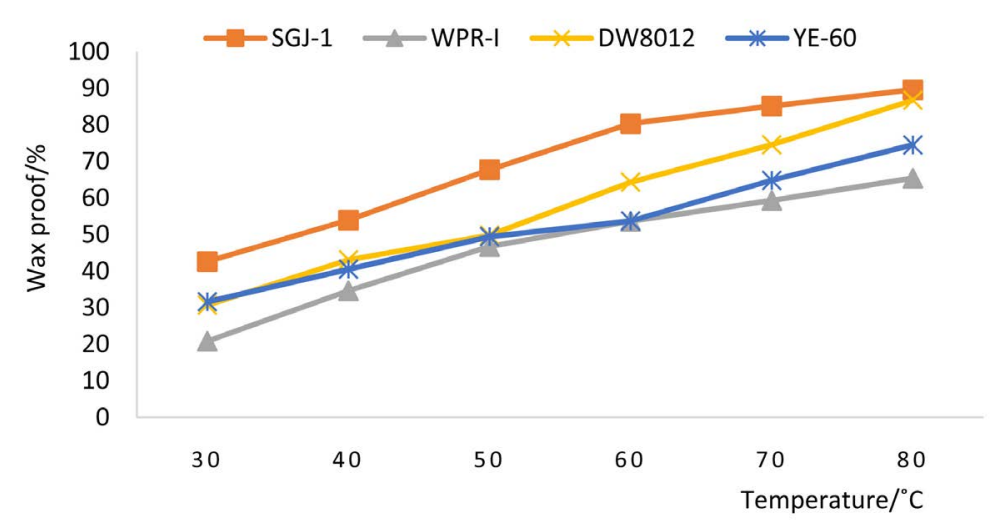

Figure 5. Variation of wax-proof rate of products at different temperature

We can see from Figure 5 that when the temperature reaches more than $60^{\circ} \mathrm{C}$, only the SGJ-1 wax-proof effect reaches more than $80 \%$. The change of wax prevention efficiency of the other three products at different temperatures is not obvious. As a result, several other products do not perform as well as SGJ-1. in dealing with different formation temperatures At the same time, it also shows that different temperature has a great influence on the anti-wax effect of water-based wax-cleaning agent. As a result, it is suggested that the formation temperature is more than $60^{\circ} \mathrm{C}$ and the effect is better when the water-based dewaxing agent is used.

\subsubsection{Effect of Different Water-Bearing Crude Oil on Wax-Proof Rate}

In addition to temperature, different water content of crude oil will also affect the anti-wax effect of water-based anti-wax agent. The crude oil is configured into different water-bearing samples, which is the underground crude oil of the simulated oil well. On this basis, we determined the change of wax resistance rate of SGJ-1 and other products in crude oil with different water content at $30^{\circ} \mathrm{C}$. The results are shown in Figure 6. 


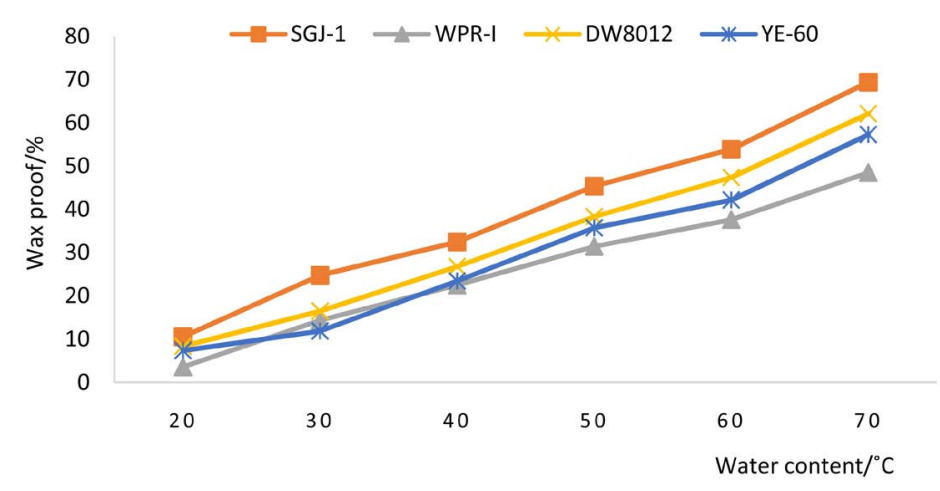

Figure 6. Variation of wax resistance rate of crude oil with different water content.

From the data of Figure 6, we can find that the anti-wax effect of water-based wax-inhibitor will increase with the increase of crude oil water content. This shows that the higher the water content of crude oil, the stronger the anti-wax performance of water-based wax-cleaning agent. Among these four products, the wax prevention rate of SGJ-1 has been in the leading position, and the wax prevention efficiency has reached $69.41 \%$, which is higher than that of the other three products.

\section{Conclusions}

1) The best formula of water-based paraffin cleaning agent SGJ-1 is: Water $75 \%+$ paraffin dispersant $15 \%+$ wetting reversion agent $1 \%+$ sodium silicate $1 \%+$ alcohol cosolvent $8 \%$.

2) Different viscosity of crude oil will affect the degree of wax formation. Low viscosity of crude oil can increase the flow rate of crude oil and reduce the degree of wax formation. The research on viscosity reduction of crude oil should not be neglected in the development of SGJ-1.

3) The paraffin prevention effect of water-based paraffin repellent agent is stronger for water-containing crude oil than for non-water-containing crude oil. It fits the work of paraffin removal and paraffin prevention for high water cut oil Wells. The paraffin proof effect is greatly affected by the temperature. When used above $60^{\circ} \mathrm{C}$, the paraffin proof rate reaches more than $80 \%$.

4) The freezing point of water-based paraffin removing agent SGJ-1 was $-34^{\circ} \mathrm{C}$, the wax dissolving rate was $0.0512 \mathrm{~g} / \mathrm{m}$, and the paraffin preventing rate was $89.58 \%$, which met the quality indexes of "Technical Conditions of Paraffin Removal and Paraffin Inhibitor for Oil Recovery" and reached the technical requirements of paraffin removing agent.

\section{Conflicts of Interest}

The authors declare no conflicts of interest regarding the publication of this paper.

\section{References}

[1] Li, K.H. (1991) Types and Development of Oil Well. Wax Remover and Drilling 
Process, No. 3, 66-67+65.

[2] Zhang, Y. (2015) Analysis and Application of Waxing Cause and Waxing Technology in Oil-Pumping. Well Chemical Management, No. 20, 120.

[3] Cheng, Z.Q. and Qiao, W.J. (2006) Application and Prospect of Chemical Anti-Wax Cleaning Agent in Jianghan Oilfield. Oil and Gas Well Testing, No. 3, 72-74+78.

[4] Li, K.H., Lu, L. and Zhang, Q. (2011) Preparation and Performance Evaluation of HS-1 of New Emulsion-Type Waxer. Journal of Changjiang University (Natural Science Edition), 8, 5-7+278.

[5] Wei, G. and Liu, X.Q. (2000) Development of Efficient Water-Based Emulsion Wax Removing Agent. Inner Mongolia Petrochemical Industry, No. 3, 8-10.

[6] Zhang, W.P. and Du, J.G. (2018) Compounding and Evaluation of An Oil-Based Anti-Wax Agent. Chemical Technology and Development, 47, 19-21.

[7] Fan, T.L. (2019) A Brief Discussion on the Research Status and Development Direction of Wax-Proofing Agent. Oil Well China Equipment Engineering, No. 12, 222-223.

[8] Bin, X. (2018) Influencing Factors Governing Paraffin Wax Deposition of Heavy Oil and Research on Wellbore Paraffin Remover. Petroleum Science and Technology, 36, 1635-1641. https://doi.org/10.1080/10916466.2018.1496113

[9] Yu, H.Y., Guo, S.H., Wang, J.Y., et al. (2016) Application and Prospect of Surfactants in Oil Fields. Petrochemical Applications, 35, 10-12+22.

[10] Li, G.Z. and Xu, J. (2004) Application of Surfactant in Oil Fields and Its. Principle Progress in Fine Petrochemical Industry, No. 2, 1-6.

[11] Xu, Y., Gao, F.B., Li, J.L., et al. (2017) Development and Field Application Test of an Emulsion-Type Anti-Wax Cleaning Agent. Petrochemical Applications, 36, 15-18.

[12] Liao, J.M., Wang, X.Y. and Wang, G.Y. (1998) A Study on New Emulsion Anti-Wax Agent. Daily Chemical Industries, No. 6, 16-20.

[13] Li, J.B., Wei, J.L., Dai, S., et al. (2018) A Study on the Antiwax Agent for Horizontal Well in Chang 6 Reservoir in Heshui Oilfield. Technical Supervision of the Petroleum Industry, 34, 36-39.

[14] Wang, J., Zhuo, X.J., Zhou, C.L., et al. (2015) A Study and Application of Water-Base Dewaxing Agent in Daqing Oilfield. Contemporary Chemical Industry, 44, 1395-1397.

[15] Xue, D., Luo, H., Chen, G. and Han, R.-Y. (2018) Experiment Design of Dynamic Paraffin Deposition and Evaluation of Water-Based Paraffin Remover. DEStech Transactions on Social Science, Education and Human Science. https://doi.org/10.12783/dtssehs/icessh2018/23851

[16] Du, J.G. (2017) Development of a New Water-Based Wax Removing Agent. Xi'an Shiyou University, Xi'an.

[17] Du, J.G., Liu, X. and Li, S.J. (2017) Preparation and Performance Evaluation of WPR-I of Water-Based Wax Removing Agent. Applied Chemical Industry, 46, 951-954.

[18] Li, J.X. and Fan, Y.F. (1985) Development and Application of Water-Based Wax Remover and Anti-Waxing Agent. Oil Field Surface Engineering, 4, 12-16+4.

[19] Huang, X.D. (2014) Research and Application of Water Base Clearing Wax-Proof YE-60. China Oil and Gas Storage, 33, 519-521+530.

[20] SY/T 6300-2009, Technical Conditions of Cleaning and Wax-Proofing Agent for Oil Recovery.

[21] Gu, Y.J. (2011) Development and Application of Water Base Clearing Wax-Proof Agent. Hebei University of Science and Technology, Shijiazhuang. 